Article

\title{
Preparation and Characterization of Bacterial Cellulose-Carbon Dot Hybrid Nanopaper for Potential Sensing Applications
}

\author{
Sakeena Quraishi ${ }^{1}$, Sven Plappert ${ }^{1,2}$, Bernhard Ungerer ${ }^{1}$, Philip Taupe ${ }^{1}$, \\ Wolfgang Gindl-Altmutter ${ }^{3}$ and Falk Liebner ${ }^{1, *(1)}$ \\ 1 Division of Chemistry of Renewable Resources, University of Natural Resources and Life Sciences Vienna, \\ Konrad-Lorenz-Straße 24, A-3430 Tulln, Austria; sakeena.quraishi@boku.ac.at (S.Q.); \\ sven.plappert@boku.ac.at (S.P.); bernhard.ungerer@auslandsdienst.at (B.U.); philip.taupe@gmail.com (P.T.) \\ 2 Université Clermont Auvergne, CNRS, SIGMA Clermont, ICCF, F-63000 Clermont-Ferrand, France \\ 3 Institute of Wood Technology and Renewable Materials, University of Natural Resources and Life Sciences \\ Vienna, Konrad-Lorenz-Straße 24, A-3430 Tulln, Austria; wolfgang.gindl-altmutter@boku.ac.at \\ * Correspondence: falk.liebner@boku.ac.at
}

Received: 19 September 2018; Accepted: 19 December 2018; Published: 29 December 2018

check for updates

\begin{abstract}
Green and facile approaches aiming at the manufacture of biocompatible paper-based optical sensors reporting the presence of photoluminescence (PL) modulating compounds is an emerging field of research. This study investigates the preparation of bacterial cellulose nanopaper containing covalently immobilized carbon dots for potential biosensing applications. Preliminary work of this feasibility study included TEMPO-mediated ((2,2,6,6-tetramethylpiperidin-1-yl)oxyl-mediated) oxidation and nanofibrillation of bacterial cellulose (TOBC) on the one hand as well as synthesis and comparative analysis of different types of carbon dots (CDs) on the other hand. The two source materials of the targeted functional nanopaper were finally linked to each other by two different $N$-(3-dimethylaminopropyl)- $N^{\prime}$-ethylcarbodiimide hydrochloride/N-hydroxysuccinimide (EDC/NHS) coupling approaches to clarify whether grafting of CDs prior to or after TOBC paper formation would be the method of choice. Synthesis of the carbon nanodots was accomplished by microwave-assisted co-hydrothermolysis of appropriate precursor compounds. After isolation and purification by dialysis particles in the single-digit nanometer-range were obtained and characterized with regard to their photoluminescence properties in terms of emission wavelength, $\mathrm{pH}$ stability, and quantum yield. All types of synthesized CDs reached their PL maxima (450-480 nm; light blue) in a narrow excitation wavelength range of 340-360 nm. Variation of molar $(\mathrm{C} / \mathrm{N})$ ratio of the $\mathrm{CD}$ precursors and substitution of the nitrogen donor EDEA by urea increased PL and quantum yield (QY), respectively. The highest relative QY of nearly $32 \%$ was obtained for CDs synthesized from citric acid and urea. PL of all CDs was virtually insensitive to $\mathrm{pH}$ changes in the range of 4-10. Tensile testing of hybrid nanopaper prepared after EDC/NHS-mediated grafting of GEA-type CDs onto TOBC $\left(0.52 \mathrm{mmol} \cdot \mathrm{g}^{-1} \mathrm{COOH}\right)$ in dispersion state revealed that both stiffness and strength are not compromised by incorporation of carbon dots, while plastic deformation and elongation at break increased slightly compared to nanopaper formed prior to decoration with CDs. Water contact angle of the nanopaper is unaffected by introduction of carbon dots which is supposedly due to the presence of surface amino- and amide groups compensating for the loss of carboxyl groups by grafting.
\end{abstract}

Keywords: bacterial cellulose; hybrid nanopaper; TEMPO oxidation; carbon dots; microwave-assisted thermolysis; EDC/NHS coupling; photoluminescence; sensing applications 


\section{Introduction}

Since the turn of the millennium, a multitude of advanced cellulosic materials has been developed. Their intriguing properties including transparence, low oxygen transmission, high mechanical strength, large specific surface, or tailor-made surface chemical and physical properties [1-3] literally invite use in both established and novel applications. Diagnostic or theranostic devices in human medicine typically rely on sensitive biosensors and event-triggered controlled release of active compounds. This is also the case for intelligent wound dressings capable of assessing critical protease concentrations in chronic wounds, for example $[4,5]$. Beyond the core features allowing for reporting critical levels of a target analyte and triggering a controlled response, respective wound dressings or biosensors interacting with living tissue are required to be biocompatible, free of potentially harmful trace compounds and should have excellent moistening capabilities. Native bacterial cellulose (BC) —an extracellular product of the metabolism of various bacteria-is an ideal material in this respect owing to its inherent purity, hydrophilicity, and mechanical characteristics [6]. These properties are the result of the particular BC nanomorphology, surface chemistry and high cellulose I crystallinity, all virtually unaffected by any harsh chemical or mechanical isolation techniques as common for wood pulp cellulose [6]. While never-dried, sterilized, and uncompressed bacterial cellulose sheets have long been commercially available for medical and cosmetic purposes [7], translucent or even transparent bacterial cellulose sheets (wound dressings) or opaque nanopaper (dipsticks) for bio-sensing applications is an emerging field of material research, such as for luminescence resonance energy transfer based nucleic acid hybridization assays [8].

Optical biosensors in wound dressings are typically composed of biocompatible transducer materials of large accessible internal surface which carry an appropriate fluorescent reporter compound non-fluorescent in bonded state [9]. The latter can be linked to the substrate by a specific peptide which is designed to interact with the respective target analyte, such as human neutrophile elastase. As a result, the fluorophore is cleaved off indirectly reporting an elastase concentration dependent optical response $[5,9,10]$. Alternatively, photoluminescent nanoparticles covalently immobilized on the transducer's surface can be used whose optical response is either triggered or quenched depending on the type and concentration of the analyte.

Optical nanoscale detection devices nowadays employ a broad variety of zero-, one-, and two- dimensional photoluminescent nanoparticles capable of frequency downconversion (Stokes behavior) or upconversion (anti-Stokes photoluminescence; PL). Colloidal core/shell semiconductor quantum dots (QD, zero dimensional) [11], wires (1D), or wells (2D) form one major class of frequency downconversion nanoparticles. They are typically equipped with passivating ligands to prevent photo bleaching and fluorescence intermittency and/or coatings to suppress agglomeration or render QDs water dispersible [12]. Fluorescent carbon-based nanomaterials constitute a more recent type of photoluminescent particles featuring Stokes behavior. This group of materials includes nanodiamonds [13], carbon nanotubes (CNTs) [14], fullerene nanoparticles [15], graphene nanoribbons [16], graphene oxide [17], graphene quantum dots [18], polymer dots [19], and carbon nanodots [20]. Rare earth metal doped nanocrystals [21] are probably the most prominent type of anti-Stokes particles. Their PL response is triggered by energy-transfer upconversion (ETU), excited-state absorption (ESA), cooperative sensitization upconversion (CSU) or photon avalanche (PA) $[22,23]$.

The combination of photoluminescent carbon nanodots with cellulosic carrier materials in fully biobased sensor devices is particularly appealing. This is due to the comparatively simple preparation of CDs, their facile covalent immobilization employing the abundance of surface functional groups introduced during the one-pot reaction, low cost of precursor compounds, high quantum yields [24] next to environmental and biological compatibility $[20,25,26]$. Even though the mechanisms triggering photoluminescence of carbon dots are still a matter of debate, there is consent that (i) doping of CDs with heteroelements, such as nitrogen [27,28], a combination of nitrogen and phosphorus [29] or a combination of nitrogen and sulfur [30], (ii) variation of the size of conjugated $\pi$ domains or (iii) 
introduction of surface functional groups carrying heteroatoms [26] are efficient means for tuning their PL properties.

In an attempt to develop a fully bio-based optical sensing system applicable in form of dipsticks or wound dressings circumventing the use of heavy metal or rare earth element based PL nanoparticles, this study investigated the preparation and properties of TOBC paper matrices covalently equipped with different types of carbon nanodots (CD) obtained from natural materials, such as glycerol, citric acid or lemon juice. Unlike semiconductor nanoparticles that can be synthesized either ex- or in-situ [31,32] of the open-porous bacterial cellulose network, CDs can be prepared ex-situ only due to the rather harsh thermolytic conditions required. Common carbodiimide coupling chemistry [33] was employed for covalent grafting of the amino-functional carbon dots onto TOBC abundant in surface carboxyl groups.

\section{Materials and Methods}

Sodium hydroxide $(\mathrm{NaOH}$, anhydrous pellets, $\geq 98 \%)$, phosphoric acid $(\geq 85 \%)$, absolute ethanol (EtOH abs. $\geq 98 \%$, denaturated with $0.5-1.5 \%$ butanone), acetone $(\geq 99.5 \%)$, sodium bromide $(\geq 99 \%)$, sodium hypochlorite solution ( $\mathrm{NaClO}$, available chlorine $10-15 \%)$, sodium chlorite $\left(\mathrm{NaClO}_{2}\right.$, p.a.), 2,2,6,6-tetramethylpiperidin-1-oxyl (TEMPO, $\geq 98 \%$ ), sodium hydrogen carbonate ( $\geq 99.5 \%$ ), quinine hemihydrate $(\geq 98 \%)$, glycerol $(\geq 99.5 \%), 2,2^{\prime}$-(ethylenedioxy)-bis-(ethylamine) (EDEA, $\geq 98.5 \%$ ), $N$-(3-dimethylaminopropyl)- $N^{\prime}$-ethylcarbodiimide hydrochloride (EDC) and $N$-hydroxysuccinimide (NHS) were purchased from Sigma Aldrich (Vienna, Austria). Hydrochloric acid ( $\mathrm{HCl}, 37 \%)$ and citric acid $(\geq 99.5 \%)$ were obtained from VWR International, LLC (Vienna, Austria) while glacial acetic acid $(\geq 99.8 \%)$ and urea $(\geq 99.5 \%)$ were purchased from Merck GmbH (Vienna, Austria) and Karl Roth $\mathrm{GmbH}+\mathrm{Co} . \mathrm{KG}$ (Vienna, Austria), respectively. Acetate buffer was prepared by adjusting the $\mathrm{pH}$ of $0.1 \mathrm{M}$ acetic acid with $0.1 \mathrm{M} \mathrm{NaOH}$ to $\mathrm{pH}$ 4.8. Phosphate buffer was prepared by adding $0.1 \mathrm{M} \mathrm{NaOH}$ to $0.1 \mathrm{M}$ phosphoric acid until a $\mathrm{pH}$ of 6.8 was reached. De-ionized water $\left(\mathrm{DI} \mathrm{H}_{2} \mathrm{O}\right)$ was used if not stated otherwise.

Bacterial cellulose (BC) was provided by the Research Centre for Medical Technology and Biotechnology (Forschungszentrum für Medizintechnik und Biotechnologie, FZMB, Bad Langensalza, Germany) as differently sized sheets suspended in ethanol. The material was produced by a static cultivation of Gluconacetobacter xylinum AX5 wild type strain on Hestrin-Schramm growth medium for 30 days at $30^{\circ} \mathrm{C}$. Following repeated alkaline treatment, the BC sheets were exhaustively washed with water and immersed in ethanol.

\subsection{Bottom-Up Synthesis of Carbon Dots}

Four different types of carbon dots were prepared by microwave-assisted hydrothermolysis (750-800 W, 10 min; ETHOS 1600 equipped with PRO 24 rotor system, EMLS, Leutkirch, Germany), using three different carbon sources (glycerol, G; citric acid, CA; lemon juice, L) and two different nitrogenous precursor compounds (urea, U; EDEA, EA). At the example of GEA-type CDs, i.e., CDs obtained from glycerol and EDEA, the impact of varying mass ratios of carbon to nitrogen source materials (corresponding to molar $\mathrm{C} / \mathrm{N}$ ratios of about 6.7 to 12.9) on PL properties was studied.

GEA-type CDs: Synthesis from glycerol and 2,2-(ethylenedioxy)-bis-(ethylamine) (EDEA) as published elsewhere [34]. In brief, $5 \mathrm{~mL}$ of glycerol $(68.4 \mathrm{mmol})$ and $2 \mathrm{~mL}$ of phosphate buffered saline (PBS) were mixed with 2, 3, 4, or $5 \mathrm{~mL}$ of EDEA (13.7-34.2 mmol), respectively (cf. above). After transferring the solution to a $25 \mathrm{~mL}$ round-bottom flask, the latter was connected to a reflux condenser and placed inside the microwave. Hydrothermolysis was conducted using the above conditions. After cooling (30 $\mathrm{min}$ ) the obtained dispersion of solid thermolysis products was centrifuged at 20,000 rpm (10 $\mathrm{min}, 4^{\circ} \mathrm{C}$ ). The supernatant was filtered through a $200 \mathrm{~nm}$ filter and subjected to dialysis against deionized water for three days using an $1 \mathrm{kDa}$ membrane. The resulting dispersion of carbon dots was then lyophilized, re-dispersed in DI water to arrive at a concentration of $400 \mu \mathrm{g} \cdot \mathrm{mL}^{-1}\left(10 \mu \mathrm{g} \cdot \mathrm{mL}^{-1}\right.$ for AFM) and stored at $4{ }^{\circ} \mathrm{C}$. 
LEA-type CDs: Following an approach for synthesis of CDs from orange juice [35] but using cleared lemon juice [36] (5 mL) instead, EDEA ( $3 \mathrm{~mL})$ as a nitrogen source both co-dissolved in $2 \mathrm{~mL}$ PBS $(10 \mathrm{mM})$. Lemon juice was prepared by squeezing halved lemons using household lemon press. Filtration and subsequent centrifugation ( $5000 \mathrm{rpm}, 15 \mathrm{~min}$ ) yielded a clear extract which was stored at $4{ }^{\circ} \mathrm{C}$ until further use. Reaction conditions and work-up procedure were as described above.

LU-type CDs: Experimental procedure as described for LEA-CDs however using $10 \mathrm{~mL}$ of lemon juice and $0.5 \mathrm{~g}$ urea [37] as nitrogenous precursor instead of EDEA.

$C A U$-type $C D$ s: Citric acid (1.0 g) and different amounts of urea $(0.5,1.0 \mathrm{~g})$ were dissolved in $10 \mathrm{~mL}$ of ultrapure water and subjected to microwave-assisted co-thermolysis, subsequent isolation, and purification as described above. Since addition of the higher amount of urea $(1.0 \mathrm{~g})$ resulted in strongly agglomerated chunks, only CAU-type CDs obtained from citric acid to urea mass ratios of 2:1 were used in this study.

\subsection{TEMPO-Mediated Oxidation and Delamination of Bacterial Cellulose}

Aiming to compare the impact of different TEMPO-oxidation protocols [38-41] on the degree of substitution of the resulting $\mathrm{BC}$ derivatives, two respective oxidation protocols were tested. As $\mathrm{BC}$ had been shipped and stored in aqueous ethanol, the latter was first quantitatively replaced by water in multiple solvent exchange steps.

Oxidation in alkaline medium: $3 \mathrm{~g}$ bacterial cellulose (dry weight) was disintegrated in about $1000 \mathrm{~mL} \mathrm{H}_{2} \mathrm{O}$ using a household blender (1 $\mathrm{min}$ ) before $0.048 \mathrm{~g}$ TEMPO, $0.3 \mathrm{~g} \mathrm{NaBr}$ and $9 \mathrm{~mL} \mathrm{NaClO}$ solution (available chlorine 10-15\%) were added. While the oxidation reaction was allowed to take place for $1 \mathrm{~h}$, the $\mathrm{pH}$-value was monitored and constantly adjusted to $10-11$ using $0.1 \mathrm{M} \mathrm{NaOH}$ and $0.1 \mathrm{M} \mathrm{HCl}$. Since the reaction mixture was too viscous to be sufficiently agitated by a magnetic stirrer, an extra overhead radial flow impeller was deployed for constant stirring $(2000 \mathrm{rpm})$. The obtained material was then repeatedly sucked-off and redispersed using a total amount of $2.5 \mathrm{~L} \mathrm{H}_{2} \mathrm{O}$ in 4 cycles ( $1 \mathrm{~L}$, three times $0.5 \mathrm{~L}$ ) and a Büchner vacuum filtration setup. In order to maintain the "never dried" state and to prevent the fibrils from agglomeration, the retentate was not allowed to fall dry. After washing $800 \mathrm{~mL} 0.1 \mathrm{M}$ sodium acetate buffer ( $\mathrm{pH} 4.8$ ) and $8 \mathrm{~g} \mathrm{NaClO}_{2}$ were added to convert residual carbonyl groups into carboxyl moieties. This second oxidation step was conducted under constant stirring (1000 rpm) at room temperature for $48 \mathrm{~h}$. The resulting slurry was exhaustively washed in a similar way as described for the initial oxidation step, however using a total amount of $3.5 \mathrm{~L} \mathrm{H}_{2} \mathrm{O}$ in 6 cycles $(1 \mathrm{~L}$, five times $0.5 \mathrm{~L}$ ). Finally the purified product was diluted to arrive at an aqueous $0.25 \mathrm{w} \%$ $(\mathrm{w} / \mathrm{v})$ suspension.

Mechanical delamination: The obtained suspension (cf. above) was adjusted to $\mathrm{pH} 8$ using $0.1 \mathrm{M}$ $\mathrm{NaOH}$ and subjected to mechanical nanofibrillation using high-pressure lab homogenizer equipment (APV 1000, APV Manufacturing Sp. z o.o., Bydgoszcz, Poland). After eight fibrillation cycles and an initial pressure of $80 \mathrm{MPa}$ a highly viscous dispersion was obtained.

TEMPO-mediated oxidation of BC in near-neutral medium (TOBC): $3 \mathrm{~g}$ bacterial cellulose (dry weight) was suspended in $700 \mathrm{~mL} 0.1 \mathrm{M}$ phosphate buffer ( $\mathrm{pH}$ 6.8) and disintegrated using a household blender (1 min). $3.39 \mathrm{~g} \mathrm{NaClO}_{2}$ dissolved in another $300 \mathrm{~mL}$ of the buffer solution and $0.048 \mathrm{~g}$ TEMPO were added. Finally, $2.25 \mathrm{~mL} \mathrm{NaClO}$ solution (available chlorine 10-15\%) was added to initiate the reaction which was then left to proceed for $40 \mathrm{~h}$ at $40{ }^{\circ} \mathrm{C}$. An extra overhead radial flow impeller was deployed to keep the viscous mixture constantly stirring at $2000 \mathrm{rpm}$. The obtained TOBC was repeatedly filtered and redispersed (8 cycles; washing: two times $1 \mathrm{~L} \mathrm{H}_{2} \mathrm{O}$, two times $1 \mathrm{~L} 0.05 \mathrm{M} \mathrm{HCl}$, four times $1 \mathrm{~L} \mathrm{H}_{2} \mathrm{O}$ ) using a Büchner vacuum filtration setup. Finally the purified TOBC was diluted to arrive at an aqueous $0.40 \mathrm{w} \%(\mathrm{w} / \mathrm{v})$ suspension.

\subsection{Preparation of TOBC and TOBC/CD Hybrid Nanopaper}

In an attempt to estimate whether the more facile covalent decoration of preformed TOBC nanopaper by simple EDC/NHS dip coupling would bear significant disadvantages compared to 
covalent grafting of $\mathrm{CDs}$ onto TOBC prior to sheet formation, these two principal approaches were tested and the obtained hybrid films were compared with CD-free TOBC reference paper.

TOBC reference paper: The $0.135 \mathrm{w} \%$ TOBC dispersion was poured into a glass frit whose porous ceramic was covered by a hydrophilic poly (vinylidene fluoride) filter ( $\varnothing 90 \mathrm{~mm}, 0.65 \mu \mathrm{m}$ pore size, Merck Millipore, Germany) which was connected to a vacuum suction flask. After the TOBC dispersion had been slowly and homogeneously drained off, the wet sheet formed was removed and placed between anti-adhesive paper, flattened with a hand-operated couch roll in a crosswise pattern and placed into a sheet dryer for $1 \mathrm{~h} 45 \mathrm{~min}$ at $60^{\circ} \mathrm{C}$ and $6 \mathrm{kPa}$. Couch roll and sheet dryer were parts of a Rapid-Köthen RK-1H integrated sheet former (PTI Laboratory Equipment, Laakirchen, Austria). The final paper had a thickness of $129 \pm 8 \mu \mathrm{m}(\mathrm{n}=25)$.

Grafting of CDs after TOBC sheet formation: The TOBC nanopaper obtained (cf. above) was consecutively equilibrated in $500 \mathrm{~mL}$ water $(40 \mathrm{~min})$ and $100 \mathrm{~mL}$ of $10 \mathrm{mM}$ acetate buffer $(20 \mathrm{~min})$, using petri dishes of appropriate size. Then, the films were submersed in a solution of $20 \mathrm{mg}$ EDC and $80 \mathrm{mg}$ NHS in $100 \mathrm{~mL}$ of $10 \mathrm{mM}$ acetate buffer $(20 \mathrm{~min})$ before transferred to $20 \mathrm{~mL}$ of a $400 \mu \mathrm{g} \cdot \mathrm{mL}^{-1}$ dispersion of GEA-type CDs in ultrapure water. Finally, the films were re-immersed in (i) $10 \mathrm{mM}$ acetate buffer (5 min), (ii) $0.1 \mathrm{M} \mathrm{NaHCO}_{3}$ buffer (10 min) and (iii) exhaustively washed with deionized water.

Grafting of CDs onto TOBC prior to sheet formation: A $200 \mathrm{~mL}$ aliquot of the $0.4 \%(\mathrm{w} / \mathrm{v}) \mathrm{TOBC}$ dispersion ( $0.8 \mathrm{~g}$ dry weight) was mixed with $250 \mathrm{~mL}$ of $10 \mathrm{mM}$ acetate buffer, shortly homogenized using an IKA Ultra-Turrax T8 (IKA ${ }^{\circledR}$ Werke GmbH \& Co. KG, Staufen, Germany) and stirred for $30 \mathrm{~min}$. Then $0.83 \mathrm{~g}$ of EDC and $3.2 \mathrm{~g}$ of NHS was added. After two hours of continued stirring $9.8 \mathrm{~mL}$ of an aqueous dispersion ( $400 \mu \mathrm{g} \mathrm{mL} \mathrm{m}^{-1}$ ) of GEA-type CDs was added and the reaction mixture was left stirring overnight. The TOBC/CD hybrid nanopaper sheet $(\varnothing 9 \mathrm{~mm})$ which was formed as described above had a thickness of $116 \pm 8 \mu \mathrm{m}(\mathrm{n}=25)$.

\subsection{Analytical Methods}

Atomic force microscopy (CD particle size, TOBC dimension): AFM-topography imaging was performed with a Dimension Icon Scanning Probe Microscope (Bruker AXS, formerly Veeco, Champs sur Marne, France) equipped with a NanoScope V control station. An OTESPA cantilever was used in tapping mode at a resonance frequency of $299-301 \mathrm{kHz}$ with a spring constant of 42 (12-103) $\mathrm{N} \cdot \mathrm{m}^{-1}$. The NanoScope $8.15 \mathrm{R} 3$ software package was used for data acquisition and the Gwyddion 2.40 software package for image processing. The fibril dimensions of TOBC were determined using an aliquot of a highly diluted dispersion (ca. $5 \mathrm{mg} \cdot \mathrm{mL}^{-1}$ ). The lengths of the fibers were measured directly as they appeared coplanar to the scan's plane while diameters were determined from the maximum height of cross sectional profiles. For diameters, every examined fiber was measured thrice over a distance of about 50-100 $\mathrm{nm}$ (depending on the appearance of the fiber sample). The different types of CDs were analyzed using highly diluted dispersions $\left(4 \mu \mathrm{g} \cdot \mathrm{mL}^{-1}\right)$ prepared from the respective stock solutions.

Dynamic light scattering (DLS): Highly diluted dispersions (see above; $4 \mu \mathrm{g} \cdot \mathrm{mL}^{-1}$ ) prepared from the respective stock solutions were analyzed in 20 runs each using a Zetasizer Nano ZS (Malvern Instruments, Worcestershire, UK) equipped with a quartz cell.

Field emission scanning electron microscopy (FEG-SEM): Surface and tearing edges of selected nanopaper sheets were imaged on a Zeiss Supra 55VP (Oberkochen, Germany) using a $2 \mathrm{kV}$ beam after being gold sputtered (Edwards S150B).

Fluorescence and UV/Vis spectroscopy: Fluorescence measurements were performed on a Hitachi F-7000 spectrophotometer (Tokyo, Japan) at $310.15 \mathrm{~K}$ and $700 \mathrm{~V}$ acceleration voltage using a slit widths of $2.5 \mathrm{~nm}$ for both excitation and emission measurements. UV/Vis spectroscopy was performed on a Lambda 35 UV/vis instrument (PerkinElmer, Waltham, MA, USA) to determine the absorbance of dilution series of the different types of synthesized CDs. 
Quantum yields were determined as described elsewhere [35] using Equation (1) and quinine sulphate (QS) as a reference (standard, st) compound.

$$
\Phi(x)=\Phi(s t) \times \frac{m(x)}{m(s t)} \times \frac{\eta^{2}(x)}{\eta^{2}(s t)}
$$

$\Phi(x)$ : quantum yield of the target sample; $\Phi(s t)$ : quantum yield of QS (54\%); $m(x), m(s t)$ are the slopes of the respective linear regression curves describing the correlation between integrated fluorescence intensity and absorbance as estimated at an emission wavelength of $350 \mathrm{~nm}$ for five different QS (reference) and CD concentration levels. The latter were prepared from respective stock solutions in a way that absorbance values of $0.02,0.04,0.06,0.08$, and 0.1 were obtained. The terms $\eta^{2}(x)$ and $\eta^{2}(s t)$ represent the squares of the refractive indices of sample (CD) and standard (QS), respectively. While the quantum yield $\Phi(s t)$ of quinine sulfate is 0.54 for a $0.1 \mathrm{M}$ solution in $\mathrm{H}_{2} \mathrm{SO}_{4}$, the refractive values of $\mathrm{H}_{2} \mathrm{O}$ and $0.1 \mathrm{M} \mathrm{H}_{2} \mathrm{SO}_{4}$ are practically the same $\left(\eta_{\mathrm{H}_{2} \mathrm{O}} \approx \eta_{0.1 \mathrm{M} \mathrm{H}_{2} \mathrm{SO}_{4}}=1.33\right)$.

The impact of $p H$ variation on photoluminescence intensity of $C D$ dispersions was studied at an excitation wavelength of $350 \mathrm{~nm}$ which was considered a good compromise regarding the photoluminescence maxima of the different types of CDs. Aliquots of the stock solution uniform for each type of $\mathrm{CD}$ (50 $\mu \mathrm{L}$ for GEA, e.g.,) were diluted in $4.95 \mathrm{~mL}$ of different aqueous media of varying $\mathrm{pH}$ to covering the $\mathrm{pH}$ range from 2 to 12 in increments of one.

\subsection{Characterization of TOBC and TOBC/CD Hybrid Nanopaper}

Degree of oxidation: was determined by conductometric titration of the introduced carboxyl groups as described elsewhere [3,42]. In brief $0.1 \mathrm{~g}$ of TOBC that was beforehand subjected to freeze-drying $\left(-80^{\circ} \mathrm{C}, 30 \mathrm{~Pa}\right)$ was thoroughly disintegrated by continued magnetic stirring $(1400 \mathrm{rpm}$, $15 \mathrm{~min}$ ) in $52.25 \mathrm{~mL}$ of millipore-grade water. After addition of $2.75 \mathrm{~mL} 0.1 \mathrm{M}$ hydrochloric acid, titration was conducted by adding a total of $5 \mathrm{~mL} 0.1 \mathrm{M} \mathrm{NaOH}$ at an increment of $25 \mu \mathrm{L}$ every $30 \mathrm{~s}$. Precise dosing was accomplished using an automated titration apparatus 800 Dosino device connected to an 856 Conductivity Module equipped with an 801 Stirrer (all Metrohm, Herisau, Switzerland). The degree of oxidation as calculated according to Equation (2):

$$
D O_{\mathrm{COOH}}=162 \cdot\left(V_{2}-V_{1}\right) \cdot c \cdot\left[w-36 \cdot\left(V_{2}-V_{1}\right) \cdot c\right]^{-1}
$$

where $V_{1}$ and $V_{2}$ represent the respective initial and final amounts of $\mathrm{NaOH}$ (in L), $c$ the molarity of $\mathrm{NaOH}$ (in $\mathrm{mol} \mathrm{L}^{-1}$ ), and $\mathrm{w}$ the dry weight $(\mathrm{g})$ of the sample.

Tensile stress measurement: The prepared TOBC and TOBC/CD hybrid nanopapers (cf. above) were cut into stripes $(5 \mathrm{~mm} \times 50 \mathrm{~mm})$ using a pair of scissors. The stripes were clamped into a universal materials testing machine (Z020, Zwick Roell, Ulm, Germany) to record the respective mechanical response profiles towards tensile stress. The latter was applied at a constant rate of deformation $(1 \mathrm{~mm}$ $\left.\min ^{-1}\right)$; free clamping length was about $20 \mathrm{~mm}$. Yield strength $\left(R_{P 0.2}\right)$ was defined as the stress at $0.2 \%$ plastic deformation.

Contact angle (CA) measurements on the TOBC reference and TOBC/CD hybrid nanopaper were conducted at room temperature and constant relative humidity of $55 \%$ using a CCD camera (Sony 93D, Model XC-77CE, 2/3 inch CCD, $11 \times 11 \mu \mathrm{m}$ pixel size, Sony City, Minato, Tokyo, Japan) and white background lighting to provide better separation between the samples and the background. The droplets ( $3 \mu \mathrm{L}$ each) were applied by a manual dosage system $(1 \mathrm{~mL}$ syringe, $\mu \mathrm{m}$ screw driven dosage). Ten seconds after the droplet had been placed onto the surface of the samples, the water contact angle was measured using the DSA1 drop shape analysis software package (KRÜSS Optronic GmbH, Hamburg, Germany). 


\section{Results and Discussion}

Aiming to develop a facile method for the preparation of fully biobased and biocompatible optical dipstick sensing systems for wound fluids, covalent immobilization of carbon dots on oxidatively modified bacterial cellulose and subsequent processing to $\mathrm{BC}$ nanopaper was investigated. In a first step different types of carbon dots were synthesized by microwave-assisted co-hydrothermolysis of appropriate precursor compounds in buffered aqueous solution. Following isolation and purification by dialysis the photoluminescence properties of the obtained carbon dots in terms of emission wavelength, $\mathrm{pH}$ stability and quantum yield were investigated.

Atomic force microscopy in combination with Gwyddion data visualization and analysis confirmed that microwave-assisted co-hydrothermolysis of the various mixtures of natural and synthetic precursor materials followed by dialysis resulted in spherical nanoparticles in the desired single-digit nanoscale range (Figure 1). As a matter of course, a minor impact of the different precursor compounds and materials is evident from the slightly different size of the obtained CDs which increases in the order LEA $(1-3 \mathrm{~nm})<$ GEA $(2-5 \mathrm{~nm})<\mathrm{LU}(4-7 \mathrm{~nm})<$ CAU $(5-10 \mathrm{~nm})$. The small size of the obtained CDs has been also confirmed by dynamic light scattering on the example of GEA- $(2.7 \mathrm{~nm})$ and LEA-type CDs $(1.5 \mathrm{~nm})$.
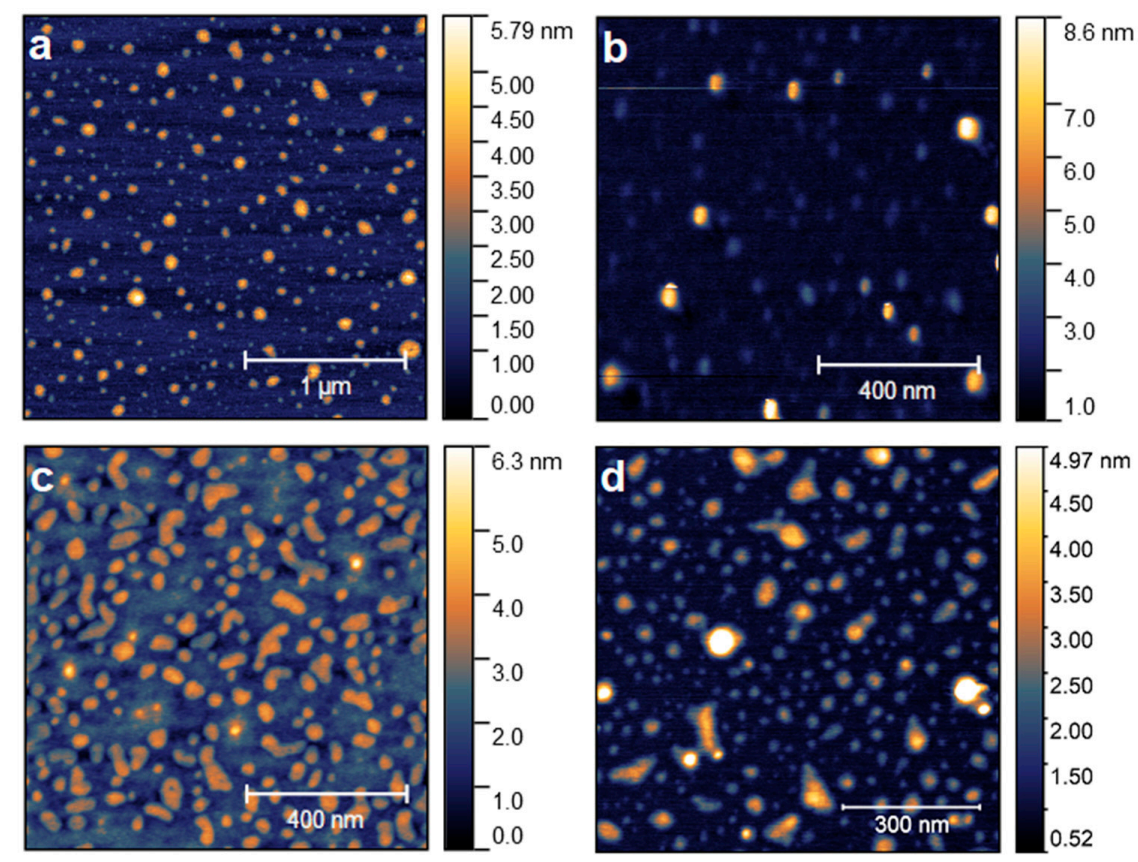

Figure 1. Atomic force microscopy (AFM) images of LEA CDs (a), GEA CDs (b), CAU CDs (c) and LU CDs (d).

All CD types prepared in this work could be easily dispersed in water. The emission maxima of $\mathrm{CDs}$ in aqueous dispersion state were reached within a narrow excitation wavelength range of $340-360 \mathrm{~nm}$. As a compromise and in favor of using a uniform excitation wavelength, all photoluminescence experiments performed to study the impact of $\mathrm{pH}$ and of the EDEA/glycerol ratio (for GEA-type CDs) on the photoluminescence intensity were conducted at $\lambda_{\text {exc }}=350 \mathrm{~nm}$.

This is virtually identical with the optimum $\lambda_{\text {exc }}$ of GEA-type CDs (351 nm) exemplarily used for the preparation of TOBC/CD hybrid nanopaper. The emission maxima ( $P L_{\max }$ ) of all types of CDs at $\lambda_{\text {exc }}=350 \mathrm{~nm}$ ranged from 450 to $480 \mathrm{~nm}$ with CAU-type CDs $(450 \mathrm{~nm})$ having the lowest and LEA-type CDs the highest values $(476 \mathrm{~nm})$. Accordingly, all CD dispersions had an intense light blue appearance under near UV light (Figure 2a). The greenish color of some crude products (cf. Figure 2a, left) is most likely caused by lower-molecular by-products which is concluded from the observation that the color changed to light blue after dialysis. Size-dependent variation of $P L_{\max }$ as reported 
for two different samples of carbon dots ( $~ 3.8 \mathrm{~nm}$ versus $\varnothing 13 \mathrm{~nm}$ ) generated by laser ablation photoluminescence [43] was not observed for our microwave-assisted hydrothermal approach and set of samples, respectively. This supports the common assumption that PL in CDs is rather governed by the size and conformation of conjugated $\pi$ electron domains next to surface effects triggered by surface defects or hetero-element surface moieties than by quantum confinement effects [44].
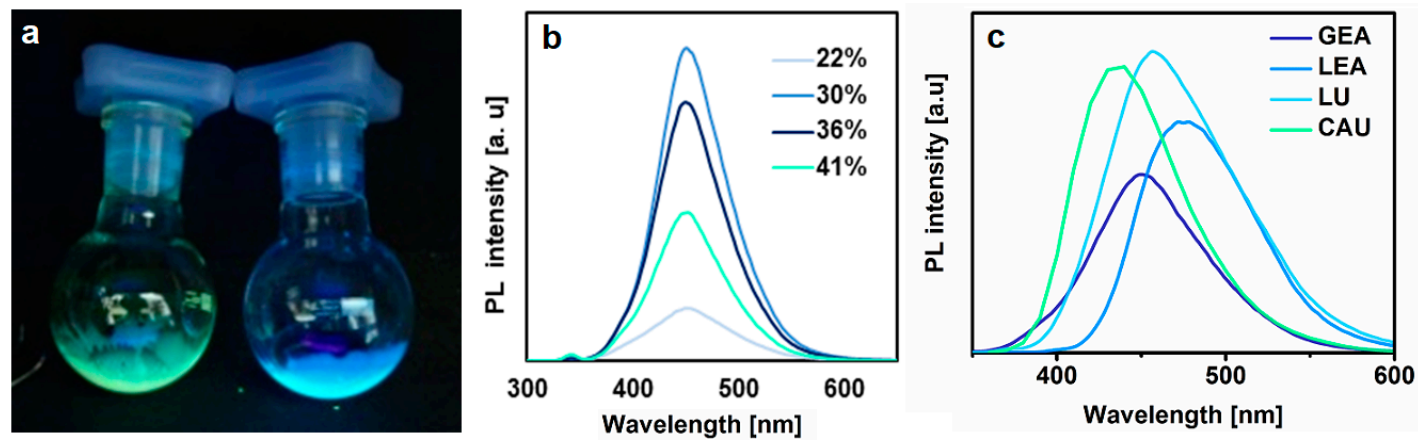

Figure 2. Pictures of aqueous dispersions of LEA (a, left) and GEA type CDs (a, right) at $\lambda_{\text {exc }}=366 \mathrm{~nm}$. Impact of the EDEA mass fraction $(22-41 \%, \mathrm{v} / \mathrm{v}$ ) in the precursor mixture (glycerol + EDEA) on PL intensity of GEA-type CDs (b). Comparison of PL characteristics of aqueous dispersions ( $\mathrm{pH}$ 6) of the different types of CDs prepared (c).

This work investigated the optimum ratio of GEA precursor compounds aiming to increase the photoluminescence properties and quantum yield. It has been shown that by variation of the glycerol-to-EDEA ratio from 80:20 to $55: 45(\mathrm{w} / \mathrm{w})$ corresponding to a molar C/ $\mathrm{N}$ ratio of 12.91 to 6.71 the PL intensity $\left(\lambda_{\text {exc }}=350 \mathrm{~nm}\right)$ could be tuned to a great extent. The highest values were obtained for molar C/N ratios of about 8-9 while the PLmax peak position remained virtually unaffected by variation of the glycerol-to-EDEA ratio. Therefore, all GEA type CDs used in this study were prepared at glycerol-to-EDEA ratio of 70:30.

In view of the planned covalent EDC/NHS-mediated coupling of aminofunctional CDs onto carboxylated surfaces of TEMPO-oxidized cellulose as well as the envisaged usage as biosensor for different types of aqueous media, the impact of varying $\mathrm{pH}$ (from 2 to 12) onto photoluminescence properties was studied. The results revealed that GEA-type CDs are virtually insensitive towards $\mathrm{pH}$ variation in this range (Figure 3a). LEA and CAU type CDs are largely stable between $\mathrm{pH} 4$ and 12, only at lower $\mathrm{pH}$ the photoluminescence intensity decreased significantly in particular for the CAU samples. Carbon dots prepared from lemon juice and urea were most sensitive towards changes of $\mathrm{pH}$ as evident from the considerable decrease of PL intensity when lowering the $\mathrm{pH}$ from 6 to 2 or rising from 6 to 12. At physiological conditions, i.e., near neutral $\mathrm{pH}$, all types of synthesized CDs however display maximum photoluminescence.

Recently, we have reported about the use of GEA-type carbon dots to impart cellulose nanocrystal (CNC) based cytocompatible materials bioimaging capabilities [45]. Besides comprehensive characterization of composition, surface functional groups and fluorescence properties we had determined their relative quantum yields-defined as ratio of emitted and absorbed photons-too. Using this quantum yield value of GEA-type CDs (14.0\% at pH 7) as a benchmark, this study confirmed the general observation that replacement of defined CD precursor compounds by natural extracts, such as by lemon juice results in carbon nanoparticles of lower quantum yield (8.4\%, LEA). 

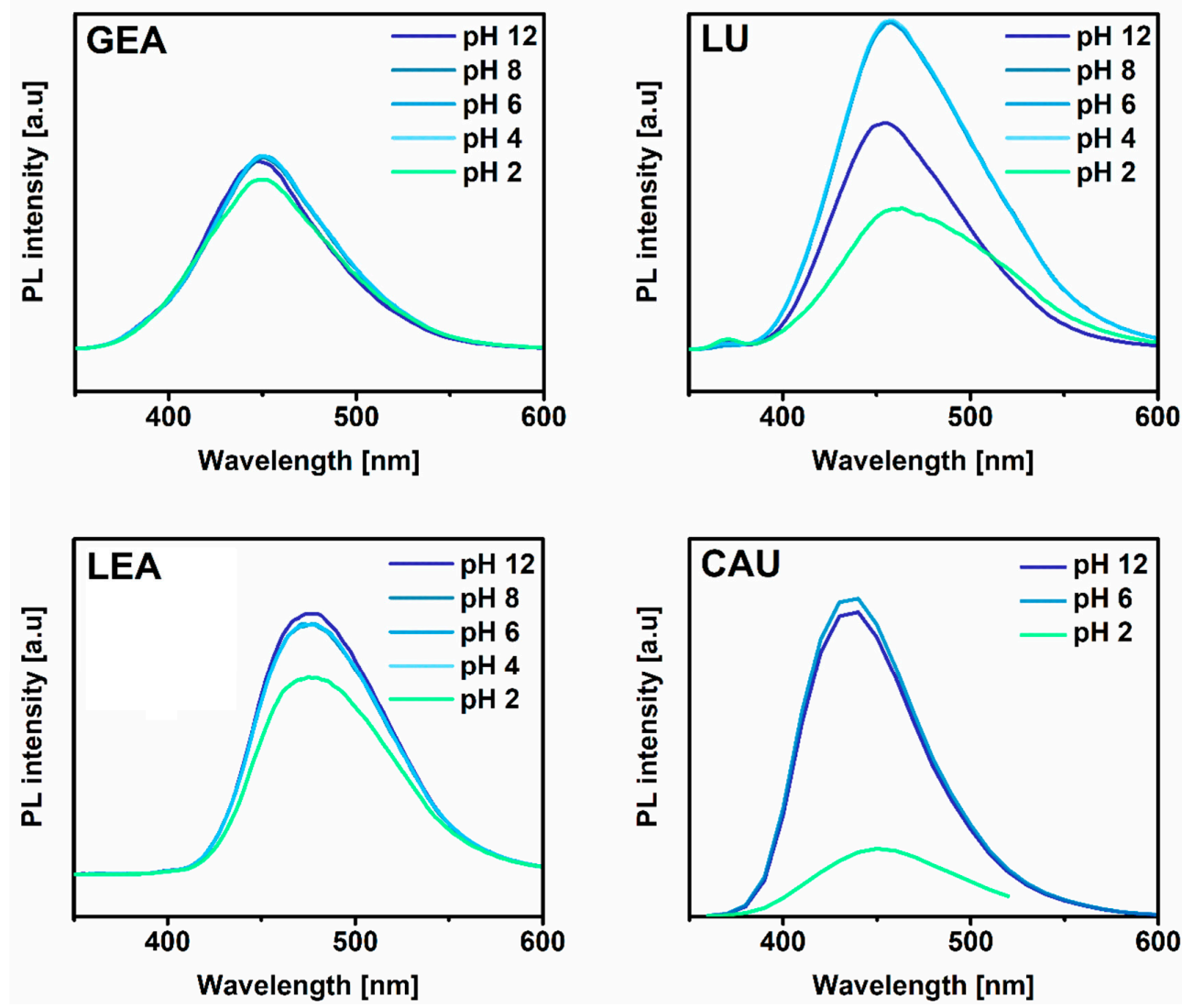

Figure 3. Impact of varying $\mathrm{pH}$ in the range from 2 to 12 on photoluminescence properties $\left(\lambda_{\text {exc }}=\right.$ $350 \mathrm{~nm}$ ) of the different types of CDs. PL: photoluminescence.

Similar low values of $5-7 \%$ had been reported for CDs prepared from sugarcane juice or strawberry juice [20], for example, and are probably caused by inorganic constituents not removed by centrifugation or filtration, and forming photoluminescent inactive particles upon pyrolysis. Interestingly, replacement of the nitrogen source 2,2'-(ethylenedioxy)-bis-(ethylamine) (EDEA) by urea considerably increased both photoluminescence intensity (Figure 2c) and quantum yield (Figure $4 a$ ) of the obtained particles in aqueous dispersion at comparable concentration. While the highest quantum yield (32\%) was obtained for CAU-type particles (citric acid/urea), a somewhat lower but still considerably high quantum yield value of $26.9 \%$ was obtained again when substituting citric acid by lemon juice (Figure 4a). It is worth noticing that the use of urea as nitrogen source resulted in materials (LU, CAU) whose PL was more sensitive towards low $\mathrm{pH}$ values (Figure $3 b, \mathrm{~d}$ ) than it was the case when EDEA was used.

Aiming to develop a facile approach for covalent bonding of carbon nanoparticles onto the surface of bacterial cellulose nanopaper we intended to compare both (i) grafting of CDs prior to and after BC nanopaper formation as well as (ii) the use of TEMPO-oxidized BC without or with subsequent nanofibrillation. To facilitate the latter, TEMPO-mediated oxidation of BC was conducted in alkaline ( $\mathrm{pH} 10-11)[38,46]$ instead of near-neutral conditions $(\mathrm{pH} 6.8)[40,41]$ aiming at the introduction of a higher density of (repulsive) surface carboxyl groups which are known to support mechanical delamination using a high-pressure homogenizer for example [47]. Following this approach two types of TOBC were obtained that differed in degree of oxidation $(D O)$ as desired and confirmed by conductometric titration (Figure $4 \mathrm{~b}$ ). While the degree of oxidation related to the count of anhydroglucose units was $8.4 \%\left(0.52 \mathrm{mmol} \mathrm{g}{ }^{-1} \mathrm{COOH}\right.$; cf. Figure $\left.4 \mathrm{~b}\right)$ for the material treated at milder conditions, it was $12.3 \%\left(0.76 \mathrm{mmol} \cdot \mathrm{g}^{-1} \mathrm{COOH}\right)$ when performing the modification in alkaline conditions. However, even at higher degree of oxidation, nanofibrillation of $\mathrm{BC}$ using a high-pressure homogenizer did not yield individualized nanofibrils as we obtained for never-dried wood pulp for 
example. AFM analysis revealed that both BC samples were partially disintegrated only, regardless whether high pressure homogenization was applied or not. While the diameters of the fibrils obtained from the stronger oxidized and mechanically delaminated $B C$ sample ranged from about 2-10 nm with an average of $5.48 \pm 0.28 \mathrm{~nm}$ (AFM, $\mathrm{n}=45$ ), those of the solely oxidized and disintegrated (kitchen mixer) material had an average fibril diameter of $9.05 \pm 2.84 \mathrm{~nm}(\mathrm{AFM}, \mathrm{n}=45$; Figure $5 \mathrm{a}, \mathrm{b})$. The average length of the fibrils - which appeared to be twisted in longitudinal direction (Figure 5b) -was somewhat below $10 \mu \mathrm{m}$ for both types of BC samples (Figure 5a). Considering aspects like cost-benefit ratio or gain of $C D$ particle density on the final surface of the opaque $B C$ nanopaper, we decided to omit the nanofibrillation step and used therefore the $\mathrm{BC}$ batch oxidized at near-neutral conditions (TOBC) for covalent coupling of CDs as described below.
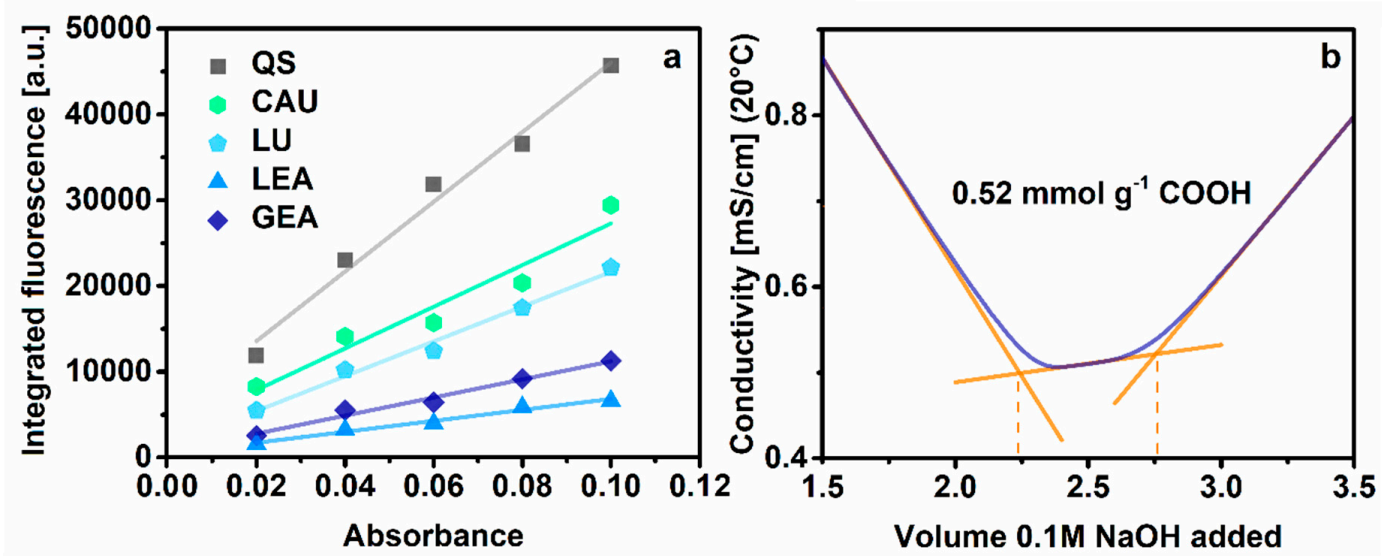

Figure 4. Relative quantum yields of the different types of carbon dots in comparison with the reference quinine sulfate (QS; a) and conductometric titration curve to determine the degree of oxidation for bacterial cellulose (BC) subjected to TEMPO-mediated oxidation at near $\mathrm{pH}$ neutral conditions (b).
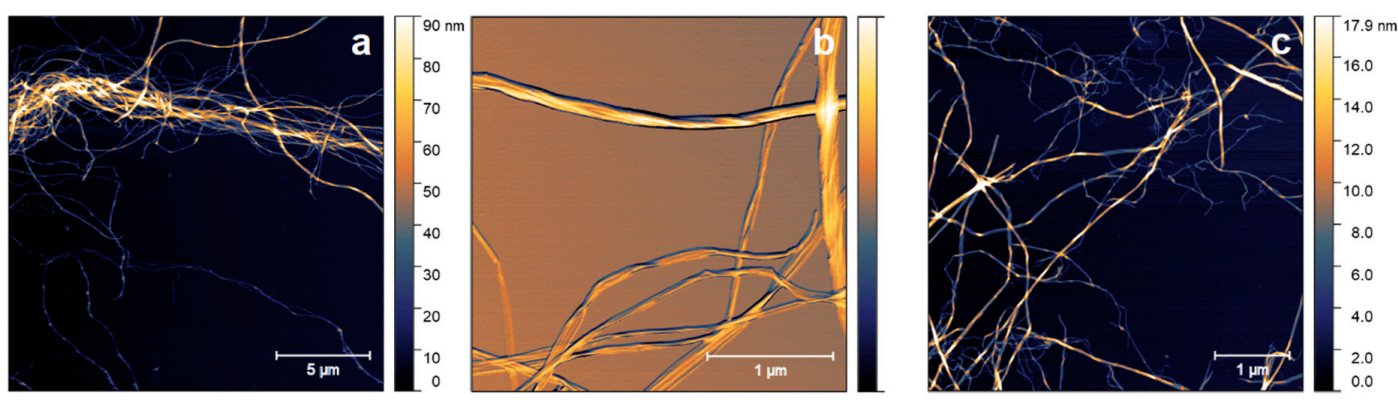

Figure 5. AFM pictures of bacterial cellulose subjected to TEMPO-mediated oxidation in aqueous near-neutral- $(\mathrm{pH} 6.8 ; \mathbf{a}, \mathbf{b})$ and alkaline conditions $(\mathbf{c})$ at different magnification.

Aiming to develop a green approach for facile manufacture of paper-based optical sensors, we employed classic aqueous EDC/NHS coupling chemistry to graft the largely bio-based and good water-dispersible CDs onto the surface of the oxidatively activated BC. For demonstration purposes we selected GEA-type CDs since we had recently comprehensively studied their EDC/NHS-mediated bonding to the surface of TEMPO-oxidized cellulose nanocrystals [45]. While X-ray photoelectron spectroscopy (XPS) and Fourier-transform infrared spectroscopy (FT-IR) had confirmed the presence of amino groups on the surface of the respective CDs, polyelectrolyte titration, and zeta potential measurements revealed a $\mathrm{pH}$ dependent charge density varying between zero $(\mathrm{pH}>8.5)$ and $+500 \mu \mathrm{mol} \cdot \mathrm{g}^{-1}$ ( $\mathrm{pH}$ 4.5). Surface sensitive analytical techniques using a quartz crystal microbalance with dissipation monitoring and Surface Plasmon Resonance complementing XPS and FT-IR measurements confirmed the establishment of covalent bonds between surface amino groups of the GEA-type CD nanoparticles and carboxyl groups on the surface of CNC. Since this study employed 
not only the same type (GEA) but also material of the same batch of carbon dots and a comparable carboxylated cellulosic substrate, successful covalent bonding of GEA CDs onto the surface of the TOBC materials can be assumed.

This is also evident from the photoluminescence properties of the final TOBC/CD hybrid nanopaper (Figure 6) and the aqueous phase obtained when forming the sheet from respective TOBC slurries that were subjected to EDC/NHS-mediated coupling with CDs prior to paper formation. While the hybrid paper exhibited strong bluish photoluminescence, the drained water was significantly depleted by fluorescent CDs increasing with residence time. This was similar for prefabricated TOBC nanopaper dip-grafted with GEA-type CDs (Figure 6). Also here, EDC/NHS-mediated dip-coupling imparted the paper surface blue photoluminescence increasing with residence time in the coupling bath.
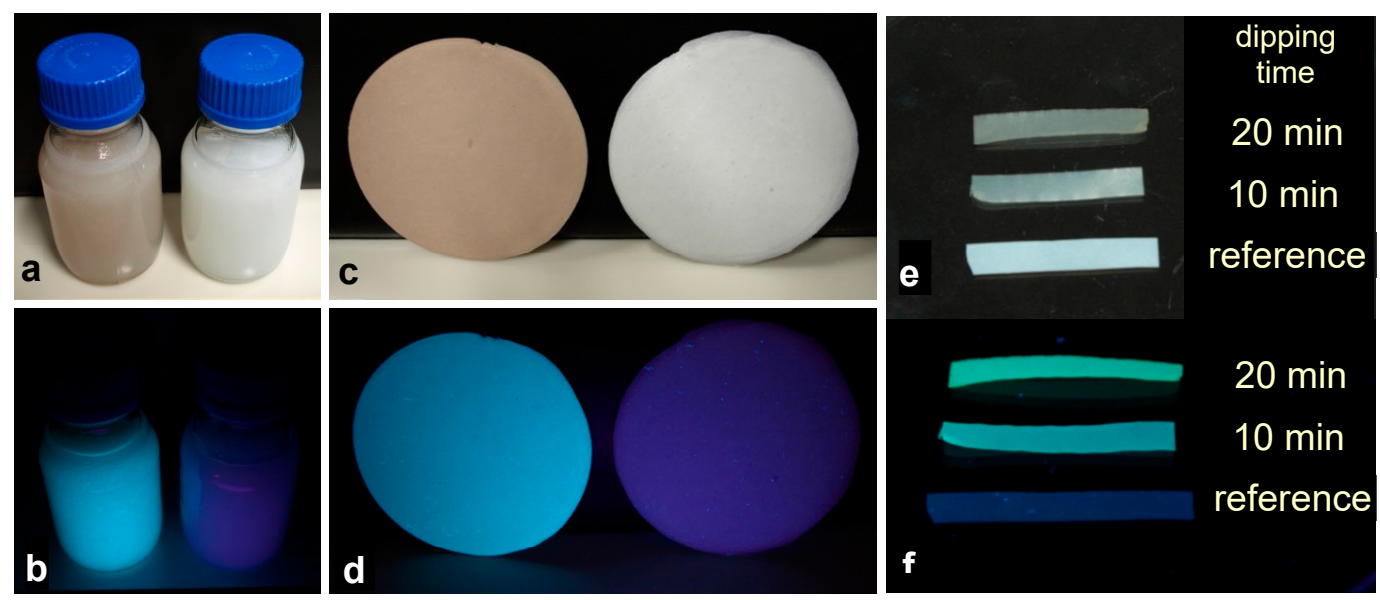

Figure 6. Aqueous suspensions of TEMPO-mediated oxidation and nanofibrillation of bacterial cellulose (TOBC) nanofibrils covalently equipped with GEA-type CDs $(\mathbf{a}, \mathbf{b})$ and nanopaper prepared therefrom $(\mathbf{c}, \mathbf{d})$ at daylight $(\mathbf{a}, \mathbf{c})$ and UV excitation (the CD-free reference material is shown in each of the pictures a-d on the right). Pictures of prefabricated TOBC nanopaper subjected to EDC/NHS-mediated dip-grafting of GEA-type CDs (10 or $20 \mathrm{~min}$ ) taken at daylight (e) or under UV light (f).

FEG-SEM images of TOBC/CD hybrid nanopaper formed after EDC/NHS-mediated grafting of GEA-type CDs onto TOBC fibrils in dispersion state revealed a dense, partly interwoven structure of entangled microfibrils (Figure 7a). At higher magnification, the typical void structure of compressed microfibrillar scaffolds is apparent suggesting the presence of rather lower void volume fractions. This is in agreement with the overall porosity of the TOBC/CD hybrid nanopaper (ca. 11.1\%) calculated from its apparent density $\left(1.345 \mathrm{~cm}^{-3}\right)$ and the skeletal density of bacterial cellulose $\left(1.582 \mathrm{~g} \cdot \mathrm{cm}^{-3}\right)$, which is marginally higher compared to the CD-free nanopaper (ca. $10.5 \%, \rho_{B}=1.354 \mathrm{~cm}^{-3}$ ).

Tensile testing of TOBC/CD hybrid nanopaper and its CD-free counterpart confirmed that EDC/NHS-mediated grafting of GEA-type CDs onto TOBC $\left(0.52 \mathrm{mmol} \cdot \mathrm{g}^{-1} \mathrm{COOH}\right)$ in dispersion state prior to paper formation does not compromise the mechanical performance of the obtained paper in terms of stiffness (tensile elasticity, Young's modulus, $E$ ) and tensile strength $R$ (yield strength) measured at $0.2 \%$ offset strain $\left(R_{p 0.2}\right)$. Plastic deformation $\left(\sigma_{\max }\right)$ and elongation at break $\left(\varepsilon_{\max }\right)$ even increased slightly with the incorporation of CDs resulting in a somewhat enhanced ultimate tensile strength (Table 1, Figure 8a). 

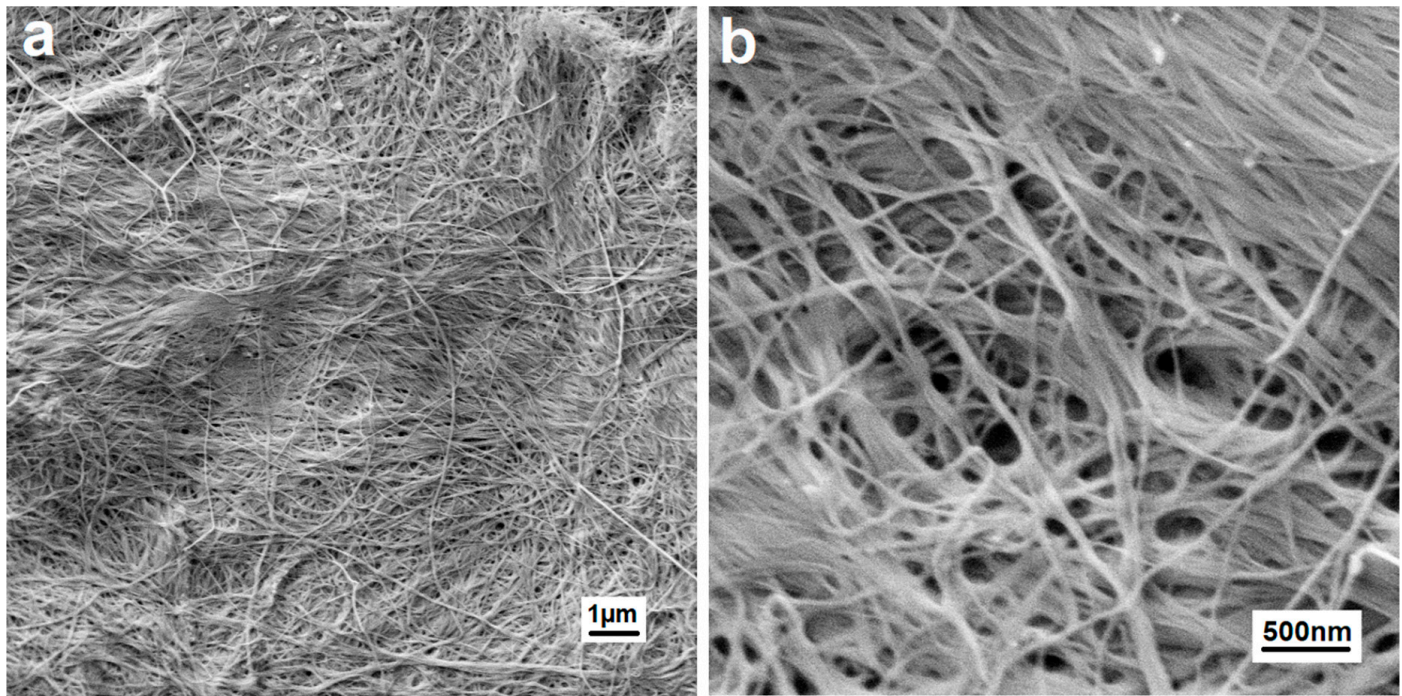

Figure 7. FEG-SEM images of TOBC/CD hybrid nanopaper at different magnification.

Table 1. Mechanical properties of TOBC nanopaper ( $3 \mathrm{~mm}$ wide, clamping length $20 \mathrm{~mm}$ ) as obtained by tensile testing.

\begin{tabular}{ccccc}
\hline & $\begin{array}{c}\boldsymbol{E} \\
{[\mathbf{G P a}]}\end{array}$ & $\begin{array}{c}\boldsymbol{R}_{\boldsymbol{p} \mathbf{0 . 2}} \\
{[\mathbf{M P a}]}\end{array}$ & $\begin{array}{c}\sigma_{\max } \\
{[\mathbf{M P a}]}\end{array}$ & $\begin{array}{c}\boldsymbol{\varepsilon}_{\max } \\
{[\mathbf{\%}]}\end{array}$ \\
\hline TOBC & $6.93 \pm 0.43$ & $60.4 \pm 1.24$ & $127 \pm 14.0$ & $4.15 \pm 0.78$ \\
TOBC/CD & $6.92 \pm 0.16$ & $55.7 \pm 2.35$ & $138 \pm 9.14$ & $5.53 \pm 0.74$ \\
\hline
\end{tabular}
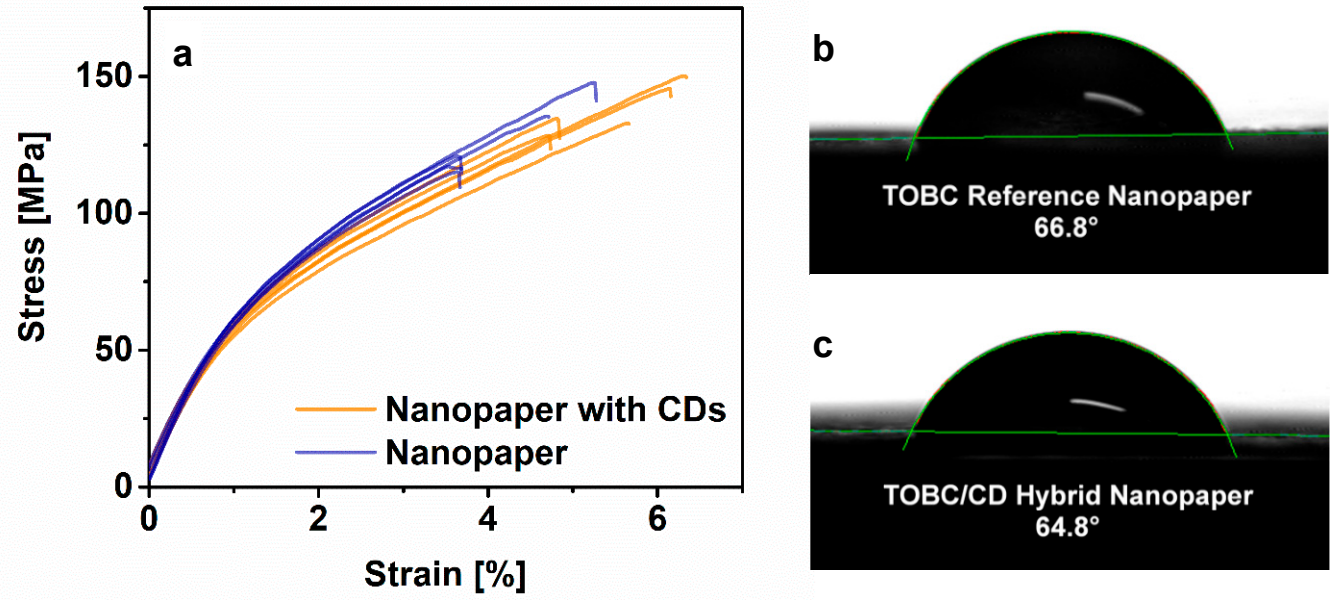

Figure 8. Response of TOBC reference and TOBC/CD hybrid nanopaper towards tensile stress (a). Water contact angle $10 \mathrm{~s}$ after a droplet had been placed on the surface of TOBC reference (b) and TOBC/CD hybrid nanopaper (c).

Water contact angle of the nanopaper is virtually also not affected by introduction of carbon dots as evident from the very similar value compared to the CD-free reference paper (Figure $8 b, c$ ). It is evident that the loss of hydrophilicity caused by EDC/NHS-mediated formation of interparticulate amide bonds between CDs and TOBC is compensated by the presence of surplus amino groups on the surface of the carbon dots.

\section{Conclusions}

This work complements two recent studies. One investigated the preparation and utilization of photoluminescent cellulose nanocrystals covalently equipped with GEA-type CDs as cytocompatible 
probes for in vitro bio-imaging of macrophage cells [45]. The second one compared the pros and cons of chemical versus physical grafting of photoluminescent amino-functional carbon dots onto nanofibrillated TEMPO-oxidized pulp cellulose for subsequent preparation of transparent photoluminescent gels and aerogels. The results of this study confirm that medically pure, biocompatible bacterial cellulose can be easily equipped with covalently immobilized photoluminescent carbon dots. Following TEMPO-mediated oxidation, optional nanofibrillation and EDC/NHS mediated grafting of aminofunctional carbon dots, the obtained dispersion of BC/CD hybrid fibrils in aqueous medium can be processed to functional nanopaper for biosensing applications. Considering the comparatively low porosity and opaqueness of the formed paper, EDC/NHS-mediated dip-grafting of aminofunctional CDs onto paper formed beforehand from TEMPO-oxidized BC is considered somewhat more efficient than grafting of the $\mathrm{CDs}$ onto $\mathrm{BC}$ fibers in aqueous suspension state prior to sheet formation. At sufficiently high degree of oxidation, it is expected that nanofibrillation in combination with flattening agents and mechanical "surface smoothing" as reported elsewhere [48] can produce transparent nanopaper. In this case, covalent grafting of CDs onto BC nanofibrils prior to paper formation would be meaningful since higher amounts of $C D$ s could be incorporated contributing to a higher PL response and, hence, sensitivity towards a respective target analyte. Even though a comparatively high relative QD of ca. 32\% was obtained for the CDs prepared from urea and citric acid, sensitivity can be probably further increased by optimizing CD synthesis in terms of precursor materials, hydrothermal conditions and purification.

Author Contributions: Conceptualization, F.L.; methodology, S.Q., S.P. and F.L.; validation, S.Q., S.P. and F.L.; formal analysis, S.Q. and S.P.; investigation, S.Q., S.P., B.U., P.T.; resources, F.L. and W.G.-A.; data curation, S.Q. and S.P.; writing — original draft preparation, S.Q. and S.P.; writing—review and editing, F.L. and S.P.; visualization, S.P.; supervision, F.L.; project administration, F.L.; funding acquisition, F.L.

Funding: This research was funded by the Austrian BMLFUW Ministry (WoodWisdom Net+ project AeroWood 2014-2017).

Acknowledgments: The authors cordially thank Johannes Konnerth and Tiina Nypelö for their support with mechanical testing and AFM analysis (University of Natural Resources and Life Sciences Vienna, Institute of Wood Technology and Renewable Materials) as well as Paul Furthmüller (University of Natural Resources and Life Sciences Vienna, Division of Biochemistry) for fluorescence measurements. The support by BOKU Vienna Open Access Publishing Fund is thankfully acknowledged.

Conflicts of Interest: The authors declare no conflicts of interest in this work.

\section{References}

1. Plappert, S.F.; Quraishi, S.; Pircher, N.; Mikkonen, K.S.; Veigel, S.; Klinger, K.M.; Potthast, A.; Rosenau, T.; Liebner, F.W. Transparent, flexible, and strong 2,3-dialdehyde cellulose films with high oxygen barrier properties. Biomacromolecules 2018, 19, 2969-2978. [CrossRef] [PubMed]

2. Plappert, S.F.; Nedelec, J.-M.; Rennhofer, H.; Lichtenegger, H.C.; Liebner, F.W. Strain hardening and pore size harmonization by uniaxial densification: A facile approach toward superinsulating aerogels from nematic nanofibrillated 2,3-dicarboxyl cellulose. Chem. Mater. 2017, 29, 6630-6641. [CrossRef]

3. Plappert, S.F.; Quraishi, S.; Nedelec, J.-M.; Konnerth, J.; Rennhofer, H.; Lichtenegger, H.C.; Liebner, F.W. Conformal ultrathin coating by scco2-mediated pmma deposition: A facile approach to add moisture resistance to lightweight ordered nanocellulose aerogels. Chem. Mater. 2018, 30, 2322-2330. [CrossRef]

4. Edwards, J.V.; Fontenot, K.R.; Prevost, N.T.; Pircher, N.; Liebner, F.; Condon, B.D. Preparation, characterization and activity of a peptide-cellulosic aerogel protease sensor from cotton. Sensors 2016, 16, 1789. [CrossRef] [PubMed]

5. Fontenot, K.R.; Edwards, J.V.; Haldane, D.; Pircher, N.; Liebner, F.; Condon, B.D.; Qureshi, H.; Yager, D. Designing cellulosic and nanocellulosic sensors for interface with a protease sequestrant wound-dressing prototype: Implications of material selection for dressing and protease sensor design. J. Biomater. Appl. 2017, 32, 622-637. [CrossRef] [PubMed] 
6. Liebner, F.; Aigner, N.; Schimper, C.; Potthast, A.; Rosenau, T. Bacterial cellulose aerogels: From lightweight dietary food to functional materials. In Functional Materials from Renewable Sources; Liebner, F., Rosenau, T., Eds.; American Chemical Society: Washington, DC, USA, 2012; Volume 1107, pp. 57-74.

7. Liebner, F.; Pircher, N.; Rosenau, T. Bacterial cellulose aerogels. In Bacterial Nanocellulose: From Biotechnology to Bio-Economy; Gama, M., Dourado, F., Bielecki, S., Eds.; Elsevier: The Netherlands, 2016; pp. 73-108.

8. Doughan, S.; Uddayasankar, U.; Krull, U.J. A paper-based resonance energy transfer nucleic acid hybridization assay using upconversion nanoparticles as donors and quantum dots as acceptors. Anal. Chim. Acta 2015, 878, 1-8. [CrossRef] [PubMed]

9. Edwards, J.V.; Prevost, N.T.; French, A.D.; Concha, M.; Condon, B.D. Kinetic and structural analysis of fluorescent peptides on cotton cellulose nanocrystals as elastase sensors. Carbohydr. Polym. 2015, 116, $278-285$. [CrossRef] [PubMed]

10. Edwards, J.V.; Fontenot, K.R.; Liebner, F.; Condon, B.D. Peptide-cellulose conjugates on cotton-based materials have protease sensor/sequestrant activity. Sensors 2018, 18, 2334. [CrossRef]

11. Shirasaki, Y.; Supran, G.J.; Bawendi, M.G.; Bulović, V. Emergence of colloidal quantum-dot light-emitting technologies. Nat. Photonics 2012, 7, 13-23. [CrossRef]

12. Mansur, H.S. Quantum dots and nanocomposites. Wiley Interdiscip. Rev. Nanomed. Nanobiotechnol. 2010, 2 , 113-129. [CrossRef]

13. Mochalin, V.N.; Shenderova, O.; Ho, D.; Gogotsi, Y. The properties and applications of nanodiamonds. Nat. Nanotechnol. 2012, 7, 11-23. [CrossRef] [PubMed]

14. Lee, A.J.; Wang, X.; Carlson, L.J.; Smyder, J.A.; Loesch, B.; Tu, X.; Zheng, M.; Krauss, T.D. Bright fluorescence from individual single-walled carbon nanotubes. Nano Lett. 2011, 11, 1636-1640. [CrossRef] [PubMed]

15. Jeong, J.; Jung, J.; Choi, M.; Kim, J.W.; Chung, S.J.; Lim, S.; Lee, H.; Chung, B.H. Color-tunable photoluminescent fullerene nanoparticles. Adv. Mater. 2012, 24, 1999-2003. [CrossRef] [PubMed]

16. Vo, T.H.; Shekhirev, M.; Kunkel, D.A.; Morton, M.D.; Berglund, E.; Kong, L.; Wilson, P.M.; Dowben, P.A.; Enders, A.; Sinitskii, A. Large-scale solution synthesis of narrow graphene nanoribbons. Nat. Commun. 2014, 5, 3189. [CrossRef] [PubMed]

17. Chen, D.; Feng, H.; Li, J. Graphene oxide: Preparation, functionalization, and electrochemical applications. Chem. Rev. 2012, 112, 6027-6053. [CrossRef] [PubMed]

18. Sun, H.; Wu, L.; Wei, W.; Qu, X. Recent advances in graphene quantum dots for sensing. Mater. Today 2013, 16, 433-442. [CrossRef]

19. Wu, C.; Chiu, D.T. Highly fluorescent semiconducting polymer dots for biology and medicine. Angew. Chem. 2013, 52, 3086-3109. [CrossRef] [PubMed]

20. Lim, S.Y.; Shen, W.; Gao, Z. Carbon quantum dots and their applications. Chem. Soc. Rev. 2015, 44, 362-381. [CrossRef] [PubMed]

21. Haase, M.; Schafer, H. Upconverting nanoparticles. Angew. Chem. 2011, 50, 5808-5829. [CrossRef]

22. Auzel, F. Upconversion and anti-stokes processes with $\mathrm{f}$ and $\mathrm{d}$ ions in solids. Chem. Rev. 2004, 104, 139-173. [CrossRef]

23. Zhou, B.; Shi, B.; Jin, D.; Liu, X. Controlling upconversion nanocrystals for emerging applications. Nat. Nanotechnol. 2015, 10, 924-936. [CrossRef] [PubMed]

24. Zhu, S.; Meng, Q.; Wang, L.; Zhang, J.; Song, Y.; Jin, H.; Zhang, K.; Sun, H.; Wang, H.; Yang, B. Highly photoluminescent carbon dots for multicolor patterning, sensors, and bioimaging. Angew. Chem. 2013, 52, 3953-3957. [CrossRef] [PubMed]

25. Wang, J.; Qiu, J. A review of carbon dots in biological applications. J. Mater. Sci. 2016, 51, 4728-4738. [CrossRef]

26. Wolfbeis, O.S. An overview of nanoparticles commonly used in fluorescent bioimaging. Chem. Soc. Rev. 2015, 44, 4743-4768. [CrossRef] [PubMed]

27. Xu, M.; He, G.; Li, Z.; He, F.; Gao, F.; Su, Y.; Zhang, L.; Yang, Z.; Zhang, Y. A green heterogeneous synthesis of n-doped carbon dots and their photoluminescence applications in solid and aqueous states. Nanoscale 2014, 6, 10307-10315. [CrossRef] [PubMed]

28. Ding, H.; Yu, S.B.; Wei, J.S.; Xiong, H.M. Full-color light-emitting carbon dots with a surface-state-controlled luminescence mechanism. ACS Nano 2016, 10, 484-491. [CrossRef] [PubMed] 
29. Chandra, S.; Laha, D.; Pramanik, A.; Ray Chowdhuri, A.; Karmakar, P.; Sahu, S.K. Synthesis of highly fluorescent nitrogen and phosphorus doped carbon dots for the detection of fe ions in cancer cells. Luminescence 2016, 31, 81-87. [CrossRef]

30. Sun, C.; Zhang, Y.; Wang, P.; Yang, Y.; Wang, Y.; Xu, J.; Wang, Y.; Yu, W.W. Synthesis of nitrogen and sulfur co-doped carbon dots from garlic for selective detection of fe(3.). Nanoscale Res. Lett. 2016, 11, 110. [CrossRef]

31. Yang, Z.; Chen, S.; Hu, W.; Yin, N.; Zhang, W.; Xiang, C.; Wang, H. Flexible luminescent cdse/bacterial cellulose nanocomoposite membranes. Carbohydr. Polym. 2012, 88, 173-178. [CrossRef]

32. Li, X.; Chen, S.; Hu, W.; Shi, S.; Shen, W.; Zhang, X.; Wang, H. In situ synthesis of cds nanoparticles on bacterial cellulose nanofibers. Carbohydr. Polym. 2009, 76, 509-512. [CrossRef]

33. Morales-Narvaez, E.; Golmohammadi, H.; Naghdi, T.; Yousefi, H.; Kostiv, U.; Horak, D.; Pourreza, N.; Merkoci, A. Nanopaper as an optical sensing platform. ACS Nano 2015, 9, 7296-7305. [CrossRef] [PubMed]

34. Junka, K.; Guo, J.; Filpponen, I.; Laine, J.; Rojas, O.J. Modification of cellulose nanofibrils with luminescent carbon dots. Biomacromolecules 2014, 15, 876-881. [CrossRef]

35. Sahu, S.; Behera, B.; Maiti, T.K.; Mohapatra, S. Simple one-step synthesis of highly luminescent carbon dots from orange juice: Application as excellent bio-imaging agents. Chem. Commun. 2012, 48, 8835-8837. [CrossRef] [PubMed]

36. Hoan, B.T.; Van Huan, P.; Van, H.N.; Nguyen, D.H.; Tam, P.D.; Nguyen, K.T.; Pham, V.-H. Luminescence of lemon-derived carbon quantum dot and its potential application in luminescent probe for detection of mo6+ ions. Luminescence 2018, 33, 545-551. [CrossRef] [PubMed]

37. Miao, X.; Qu, D.; Yang, D.; Nie, B.; Zhao, Y.; Fan, H.; Sun, Z. Synthesis of carbon dots with multiple color emission by controlled graphitization and surface functionalization. Adv. Mater. 2018, 30, 1704740. [CrossRef] [PubMed]

38. Saito, T.; Nishiyama, Y.; Putaux, J.L.; Vignon, M.; Isogai, A. Homogeneous suspensions of individualized microfibrils from tempo-catalyzed oxidation of native cellulose. Biomacromolecules 2006, 7, 1687-1691. [CrossRef] [PubMed]

39. Okita, Y.; Fujisawa, S.; Saito, T.; Isogai, A. Tempo-oxidized cellulose nanofibrils dispersed in organic solvents. Biomacromolecules 2010, 12, 518-522. [CrossRef] [PubMed]

40. Saito, T.; Hirota, M.; Tamura, N.; Kimura, S.; Fukuzumi, H.; Heux, L.; Isogai, A. Individualization of nano-sized plant cellulose fibrils by direct surface carboxylation using tempo catalyst under neutral conditions. Biomacromolecules 2009, 10, 1992-1996. [CrossRef]

41. Saito, T.; Hirota, M.; Tamura, N.; Isogai, A. Oxidation of bleached wood pulp by tempo/naclo/naclo2 system: Effect of the oxidation conditions on carboxylate content and degree of polymerization. J. Wood Sci. 2010, 56, 227-232. [CrossRef]

42. da Silva Perez, D.; Montanari, S.; Vignon, M.R. Tempo-mediated oxidation of cellulose iii. Biomacromolecules 2003, 4, 1417-1425. [CrossRef]

43. Hu, S.; Liu, J.; Yang, J.; Wang, Y.; Cao, S. Laser synthesis and size tailor of carbon quantum dots. J. Nanopart. Res. 2011, 13, 7247-7252. [CrossRef]

44. Zhu, S.; Song, Y.; Zhao, X.; Shao, J.; Zhang, J.; Yang, B. The photoluminescence mechanism in carbon dots (graphene quantum dots, carbon nanodots, and polymer dots): Current state and future perspective. Nano Res. 2015, 8, 355-381. [CrossRef]

45. Guo, J.; Liu, D.; Filpponen, I.; Johansson, L.S.; Malho, J.M.; Quraishi, S.; Liebner, F.; Santos, H.A.; Rojas, O.J. Photoluminescent hybrids of cellulose nanocrystals and carbon quantum dots as cytocompatible probes for in vitro bio-imaging. Biomacromolecules 2017, 18, 2045-2055. [CrossRef]

46. Okita, Y.; Saito, T.; Isogai, A. Entire surface oxidation of various cellulose microfibrils by tempo-mediated oxidation. Biomacromolecules 2010, 11, 1696-1700. [CrossRef]

47. Isogai, A.; Saito, T.; Fukuzumi, H. Tempo-oxidized cellulose nanofibers. Nanoscale 2011, 3, 71-85. [CrossRef] [PubMed]

48. Nogi, M.; Iwamoto, S.; Nakagaito, A.N.; Yano, H. Optically transparent nanofiber paper. Adv. Mater. 2009, 21, 1595-1598. [CrossRef]

(C) 2018 by the authors. Licensee MDPI, Basel, Switzerland. This article is an open access article distributed under the terms and conditions of the Creative Commons Attribution (CC BY) license (http:/ / creativecommons.org/licenses/by/4.0/). 